\title{
Experimental model for the evaluation of metabolic status after gastric
}

\section{bypass in obese rats}

\author{
Radu Mihail Mirica ${ }^{1,2}$, Mihai Ionescu ${ }^{5}$, Alexandra Mirica ${ }^{4,6}$, Octav Ginghina ${ }^{1,2}$, Razvan Iosifescu ${ }^{1,2}$, Adrian \\ Rosca $^{3}$, Claudiu Ungureanu ${ }^{1}$, Andrei Vacarasu ${ }^{1}$, Leon Zagrean ${ }^{3}$, Nicolae Iordache ${ }^{1,2}$
}

\begin{abstract}
Objective: Obesity is an exceedingly current pathology with many clinical, molecular, and psychological implications. The number of obese people has doubled in the past ten years, and we can observe an early onset of obesity. Bariatric surgery is an effective treatment for severe obesity and type 2 diabetes mellitus (T2DM); Roux-en-Y gastric bypass (RYGB) and sleeve gastrectomy (SG) are the two most prevalent types of this procedure . Nevertheless, no single mechanism has emerged that thoroughly explains the metabolic benefit and subsequent long-term effects after surgery. Webster's new collegiate dictionary defines the noun model as: 'a descriptive or analogy used to help visualize something that cannot be directly observed.' Sustained by this definition, the animal models in nutritional research are fundamental to improve human conditions. Due to the recent boost in experimental surgery, our aim in this study is to set the main technical characteristics of the gastric bypass operation and specific animal care in the metabolic surgery field we have been undertaking in our center.
\end{abstract}

Materials and methods: We chose Wistar rats fed with a high caloric diet (HCD) 82g / $100 \mathrm{~g}$ fat, 53/100 g saturated fat, 64/100 g carbohydrates. After 7-15 weeks of this diet, depending on the protocol understudy, a consistent three-fold greater weight gain is achieved than the usual range of the free eating chow. After approximately three months on an $\mathrm{HCD}$, the obese rats manifest biochemical features of the metabolic syndrome.

Results: The weight loss for group B (By-pass) was $125 \pm 16.16 \mathrm{~g}$, and for group BS (By-pass + Sulodexid), it was $133.10 \pm 14.38 \mathrm{~g}$. Although the weight loss was higher in group BS, it is not statistically significantly higher than in group B $(\mathrm{p}=0.345)$, despite administering a pharmacologically active substance in group BS. Although small (approximately $40-50 \mathrm{~g}$ ), the difference between the control group and groups B and BS is statistically significant with $\mathrm{p}$ $=0.016$ and 0.026 and Pearson index of 0.674 and 0.628 , respectively. Statistical significance also kept the difference between group $\mathrm{C}$ and group $\mathrm{S}(\mathrm{p}=0.028$, Pearson Coefficient $=0.621)$.

Conclusions: First of all, Metabolic surgery is the most effective weight-loss method and improvement or even remission of some diseases associated with obesity. Like today's high-calorie diet, the diet administered, mostly of adolescents, generates both obesity and its associated diseases: diabetes, hypertriglyceridemia, hypercholesterolism, thus increasing mortality and overall morbidity. Second, metabolic surgery radically improves the parameters targeting obesity (weight,\% EBWL) and its associated conditions: diabetes mellitus, hypertriglyceridemia, hypercholesterolemia, strongly associated with decreasing life expectancy of the general population. Parameters targeted by gastric bypass: glycemia, TGL, CHO, hepatic steatosis, testicular atrophy registering significant improvements.

Keywords: Gastric bypass, Obesity, Hypercaloric nutrition

\section{Introduction}

The worldwide pandemics of obesity and diabetes are devastating in severity, extent, and rate of growth. Over two billion adults worldwide, approximately $30 \%$ of the population are either overweight (body mass index $(\mathrm{BMI})>$ $25)$ or obese $(\mathrm{BMI}>30)(1)$.
Obese patients have substantially increased morbidity and mortality from obesity-related complications, including type 2 diabetes mellitus (T2DM), cardiovascular disease, and several types of cancer (2). 
In addition to obesity in the adult population, the obesity rate amongst children and adolescents in the USA has doubled during the past two decades. Currently, $17 \%$ of children aged 2-19 years are obese (3). If this trend continues, obesity and its associated co-morbidities threaten the health of future generations. Given the severity of the obesity pandemic, there is an urgent need for a detailed understanding of the mechanisms underlying the pathophysiology of obesity to enable effective therapy.

There is a limited understanding of the precise mechanisms by which RYBGBP induces and maintains substantial weight loss. In continuous numerical growth, evidence for this hypothesis suggests that profound changes in body weight and metabolism cannot be explained by simple mechanical restrictions or by malabsorption techniques of gastric bypass. $(4,6)$. Several groups have shown that gastric bypass affects hunger and increases or accelerates the experience of satiety after meals. Gastric bypass has been shown to alter the release of various gastrointestinal hormones, including ghrelin, GLP-1, YY peptide, and glucose-dependent insulinotropic peptide, generating an endocrine response that results in a drastic reduction in appetite and early postprandial satiety. (5).

In the absence of effective non-invasive treatments, bariatric surgery remains the only practical option that can lead to long-term sustained weight loss (6-8). In RYGB (Fig. 1a), the stomach is divided into two sections, creating a small gastric pouch (about $1-2 \%$ of total gastric volume) $(9,10)$. The small intestine is also divided and rearranged to create Y-shaped anatomy, causing the food to bypass the more extensive section of the stomach and upper intestine, restricting stomach capacity and proper intestine length . Although the development of laparoscopic methods has substantially reduced the mortality and complications associated with RYGB, it is still a complex operation that can lead to postoperative complications (about $0.5 \%$ mortality rates), after which patients require intensive postoperative care and life-long nutritional management(11-13).

Another view on adipose tissue and obesity was due to research that led to the discovery of leptin and the identification of adiponectin, and later, after two years and other protein structures specific to adipose tissue both visceral and subcutaneous, having hormonal activity, both autocrine and paracrine. It is well known today that adipose tissue has an extraordinarily complex and insufficiently documented role(14).

What is the future of adipose tissue as an endocrine organ? This is a question that not only endocrinologists but also metabolic surgeons ask themselves. Several hormones derived from adipose tissue have been identified, but even those factors that are relatively well known, such as leptin, require further evaluation to precisely define their physiological roles. In addition to known genes, up to $40 \%$ of genes expressed in adipose tissue are newly discovered genes, and $20-30 \%$ of them can secrete proteins. Ongoing research into these new genes aims to reveal a more indepth perspective on adipose tissue's endocrine function and the relationship between energy homeostasis and other physiological systems (14-16).
Further studies are also needed to clarify the contribution of adipose tissue's individual cellular components to determine how these components function as a unit. Finally, understanding the endocrine function of adipose tissue is likely to allow for more rational approaches to treating the metabolic consequences of excess and deficiency of fatty tissue. (17)

\section{Material and Methods}

Experimental design included a number of 40 Wistar rats divided into four lots (exemplified below). They were fed for 12-16 weeks with a high-calorie diet (with a very high energy value) consisting of $82 \mathrm{~g} / 100 \mathrm{~g}$ fat, 53/100 g saturated fat, 64/100 g carbohydrates; they were practically fed $82 \%$ butter and carbohydrate-enriched chocolate to reach the stage of obesity, weighing over the 75th percentile of age. These were added discretionary feeding with rat granules and water ad libitum with $35 \mathrm{~g}$ sugar / 100 $\mathrm{g}$ water. Thus, an attempt was made to simulate a hyperlipidemic hyperglycemic diet found today in the daily diet of the population that consumes fast food and sweet carbonated drinks. The exception to this rule is the control group throughout the experiment, the regular diet specific to laboratory animals with grains and water ad libitum. .Thus, we tried to simulate a hyperlipidemic hyperglycemic diet that is found today in the daily diet of the population that consumes fast food and sweet carbonated drinks. Subsequently, they underwent gastric bypass surgery. They were kept permanently in individual cages at a temperature of $21 \pm 3$ degrees Celsius and 45$60 \%$ humidity, with specific water and granules for ad libitum feeding and 3-5 hypercaloric meals (described above) per day (except for the control group). (Figure 1). Reaching the weight of over 75 th percentile (declared obese), those in groups 2 and 4 were operated on. At the time of surgery, blood samples were collected to analyze the above parameters. After 28 days, they were sacrificed, at which time biological samples were collected again, intraperitoneal characters were studied, and organs were collected for further study.

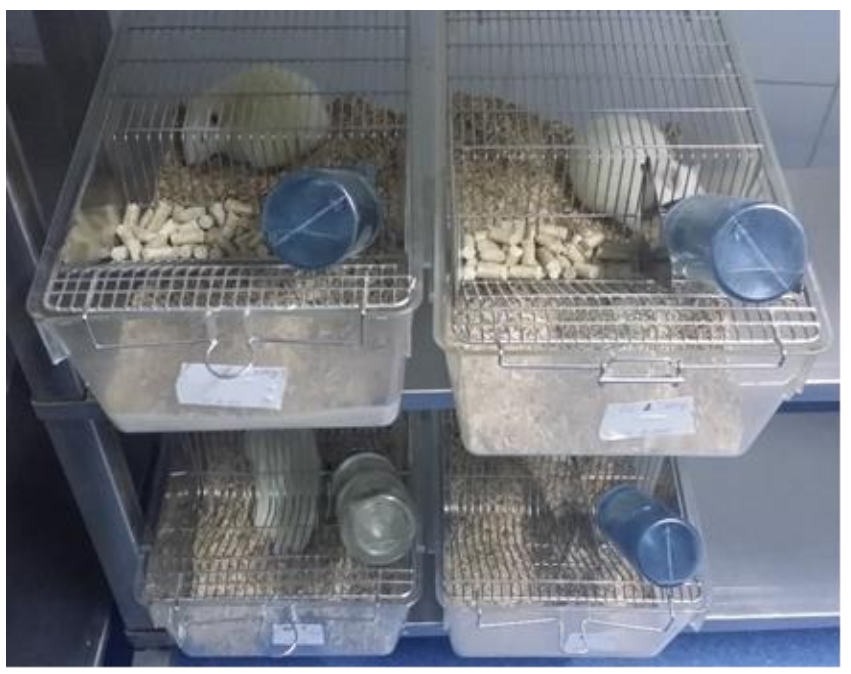

Figure 1. Rats in individual cages

Anesthesia and pain control was performed, following a pre-weighing, by weight, with an anesthetic mixture of 
Acepromazine $(0.2 \mathrm{ml} / \mathrm{kg})$ and Ketamine $(100 \mathrm{mg} / \mathrm{kg}$ ) administered intramuscularly. If necessary, during the surgery, $0.1 \mathrm{ml}$ of Ketamine was administered for better anesthetic control. The sulodexide solution provided by Alfa Sigma Company was administered by intramuscular injection.

Before the day of surgery, 18-24 hours, the rats were deprived of oral nutrition, being only hydrated with water ad libitum. The equipment consists of: a scalpel, anatomical and surgical forceps, 2 Pean forceps, 2 Kocher forceps, a dissection scissors, and a needle holder. The sutures used were polyglactin 4-0 (Vicryl) for anastomoses and polypropylene or polyglactin 3-0 or 4-0 for layer closure.

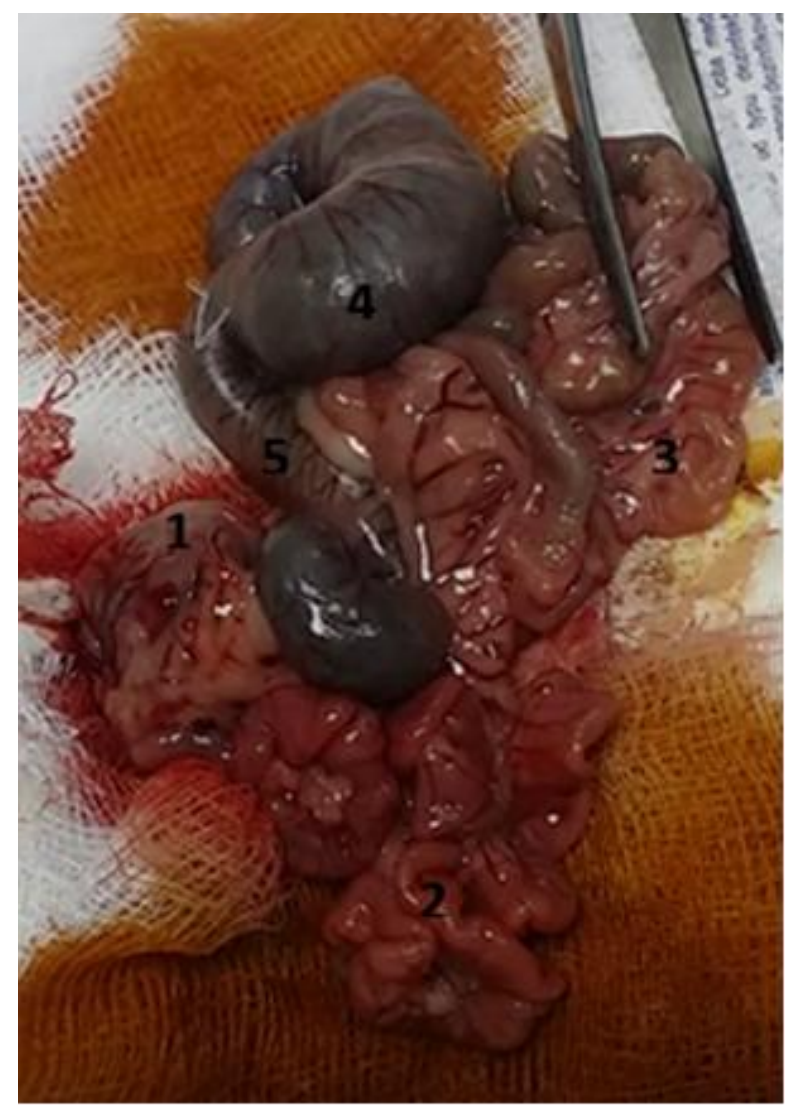

Figure 2: Peritoneal cavity inspection with identification of anatomical landmarks: 1- stomach, 2- jejunum, 3- ileum, 4check, 5- transverse colon.

The operating device included The rat beeing fixed to the heated operating table, with the abdomen prepared for the incision. Sterile operating field Autoclave or bead sterilize instruments before use. Prepare an aseptic operative field by covering the operation table with a sterile drape. Place the sterile surgical instruments and a heating pad on the table. Turn on the heat pad and set the temperature to $37{ }^{\circ} \mathrm{C}$. Cover the heating pad with a sterile drape. Set up the rodent anesthesia machine.

The sterile operating field is followed by laparotomy on a length of about $3 \mathrm{~cm}$ (Laparotomy: skin incision sectioning of the right abdominal muscles - penetration into the peritoneal cavity without damaging the internal organs). After entering the peritoneal cavity, it is inspected, and the targeted anatomical elements are identified (Figure 2).
A gastric reservoir of approximately $1 / 4$ of the total surface of the stomach is made by pinching and sectioning it with scissors, After a minimal dissection at the small gastric curvature level and the Hiss angle to enter the retro gastric space. (Figure 3)

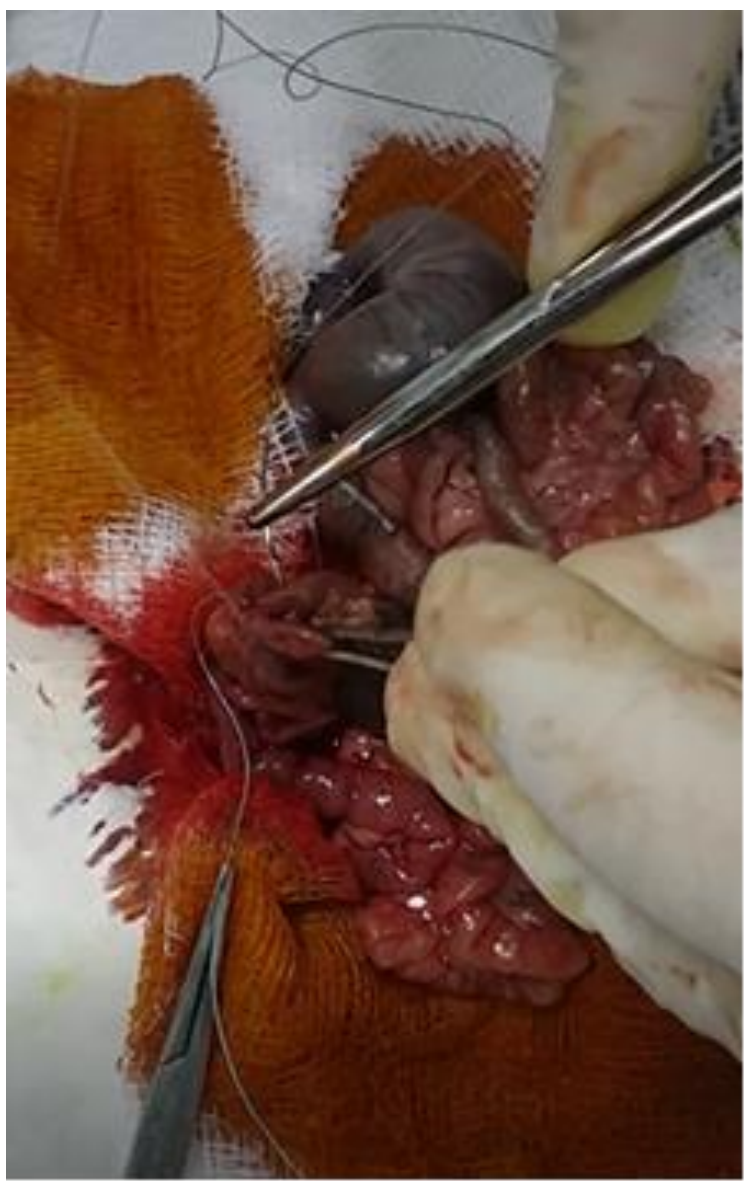

Figure 3: Closing with a 3-0 or 4-0 thread in the surget of the remaining stomach

Close the remaining stomach with a thread in the thigh as in the image below and then proceed to prepare the jejunal loop to be anastomosed to the gastric trench of the gastric reservoir. The small intestine is sectioned approximately 16 $\mathrm{cm}$ from Treitz's angle, this being the biliopancreatic loop. Hoffmaster-Finsterer T-L gastro-jejunal anastomosis is performed with two 4-0 threads, one for the posterior layer and one for the anterior layer. (figure 3) The jejune-jejunal anastomosis is made at about $25 \mathrm{~cm}$ from the gastrojejunal anastomosis, thus remaining for the food loop $25 \mathrm{~cm}$ and the common one around 20-25 cm. Hemostasis is checked and supplemented, where necessary (Figure 4,figure 5 and figure $6 \mathrm{~A}$ and $\mathrm{B}$ ).

Parietoraphy is done on anatomical layers with 3-0 threads in the surget. (Figure 7) Wash the wound and leave the rat to wake up spontaneously from anesthesia. The temperature and pulse are monitored continuously throughout the operation. 


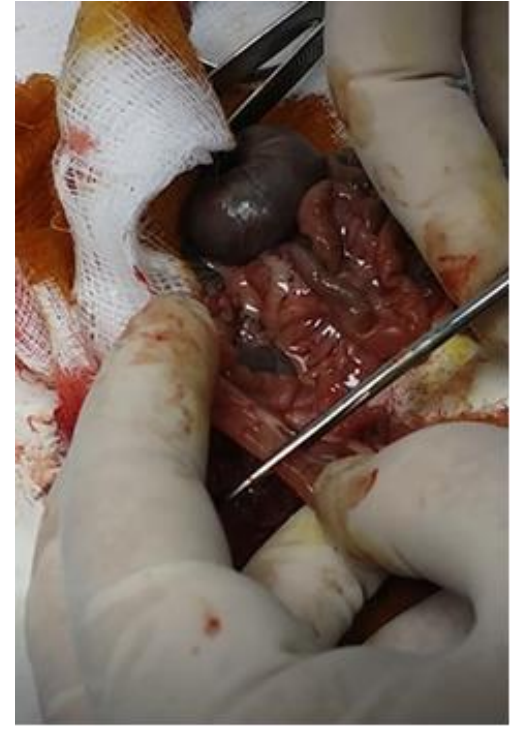

Figure 4: Preparation and sectioning of the small intestine after measuring $16 \mathrm{~cm}$ of biliary-pancreatic loop.

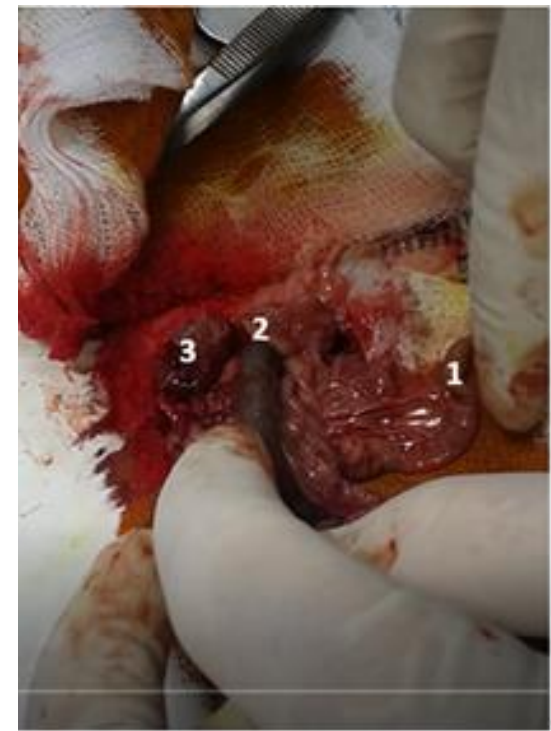

Figure 5: Beginning of gastrojejunal anastomosis: 1biliary pancreatic loop, 2- food loop, 3- gastric reservoir.

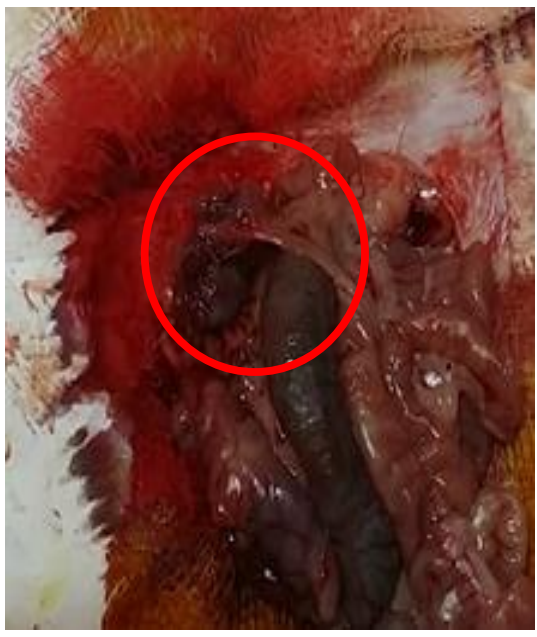

Figure 6A: The final appearance of gastrojejunal anastomosis

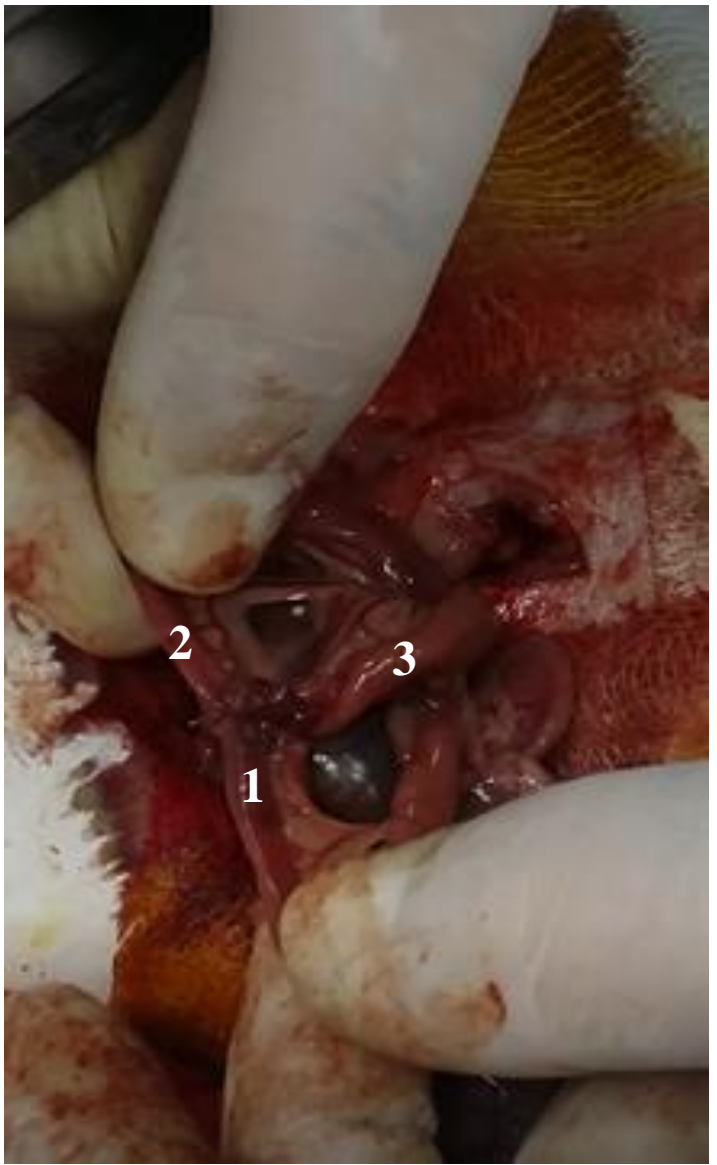

Figure 6B: Final appearance of jejuno jejunal anastomosis: 1- biliopancreatic loop, 2- food loop, 3- common loop

The average duration of such an intervention was around 55-70 min. The first 48 hours postoperatively, rehydration fluids are administered without resuming a solid oral diet.

For all rats, when the intestinal transit for feces is resumed, the appearance of possible postoperative complications is followed (the most frequently cited in the literature are the digestive fistula and the thromboembolic complications.

The subjects are 28 days after the operation period corresponding to 10-14 months in human subjects. After the anesthetic induction, which is done according to the same protocol mentioned above, the median laparotomy is performed with penetration into the abdominal cavity where the cavity is inspected, and the volume is evaluated, the quality of parietal-visceral and visceral-visceral adhesions and neovascularization is assessed on a scale specific to each rat (using the van der Ham scale - see table below: Table 1).

After adhesiolysis is performed, such a rating is also given for the appearance and quality of the anastomosis, according to the table below (Table 1.). 


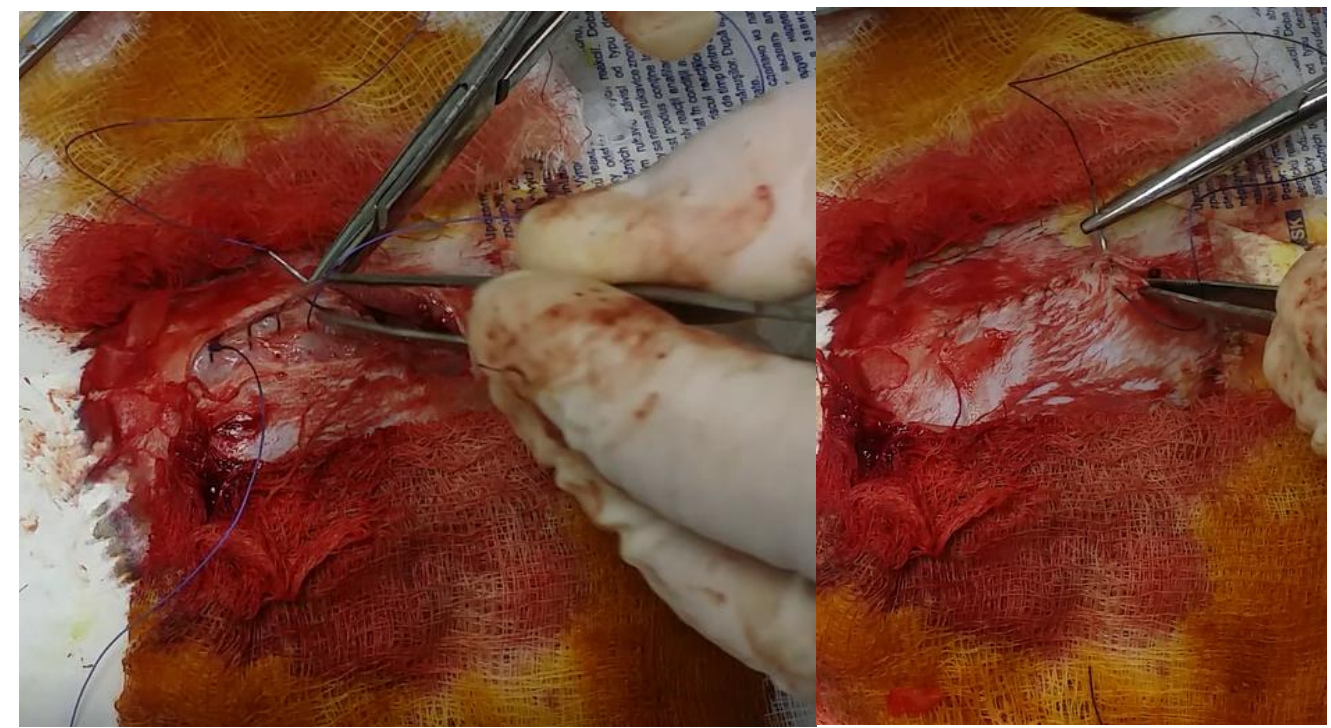

Figure 7: Anatomical parietorrhaphy with two resorbable threads in the surjet

Table 1: Table of quantitative and qualitative evaluation of intraperitoneal adhesions and the appearance of anastomoses

\begin{tabular}{|c|c|c|c|c|c|c|c|c|c|c|c|c|c|c|}
\hline \multicolumn{15}{|c|}{ Scala van der Ham } \\
\hline \multirow[b]{2}{*}{$\begin{array}{l}\text { Post operative } \\
\text { day }\end{array}$} & \multicolumn{3}{|c|}{ GJ anastomosis } & \multicolumn{3}{|c|}{ Adesiolisis } & \multicolumn{3}{|c|}{ Neovascularisation } & \multicolumn{4}{|c|}{$\mathrm{JJ}$ anastomosis } & \multirow[b]{2}{*}{$\begin{array}{l}\text { Inflamation/ } \\
\text { fistula }\end{array}$} \\
\hline & + & ++ & +++ & $(<3)$ & $(3-5)$ & $(>5)$ & + & ++ & +++ & - & + & ++ & +++ & \\
\hline 28 & & & & & & & & & & & & & & \\
\hline
\end{tabular}

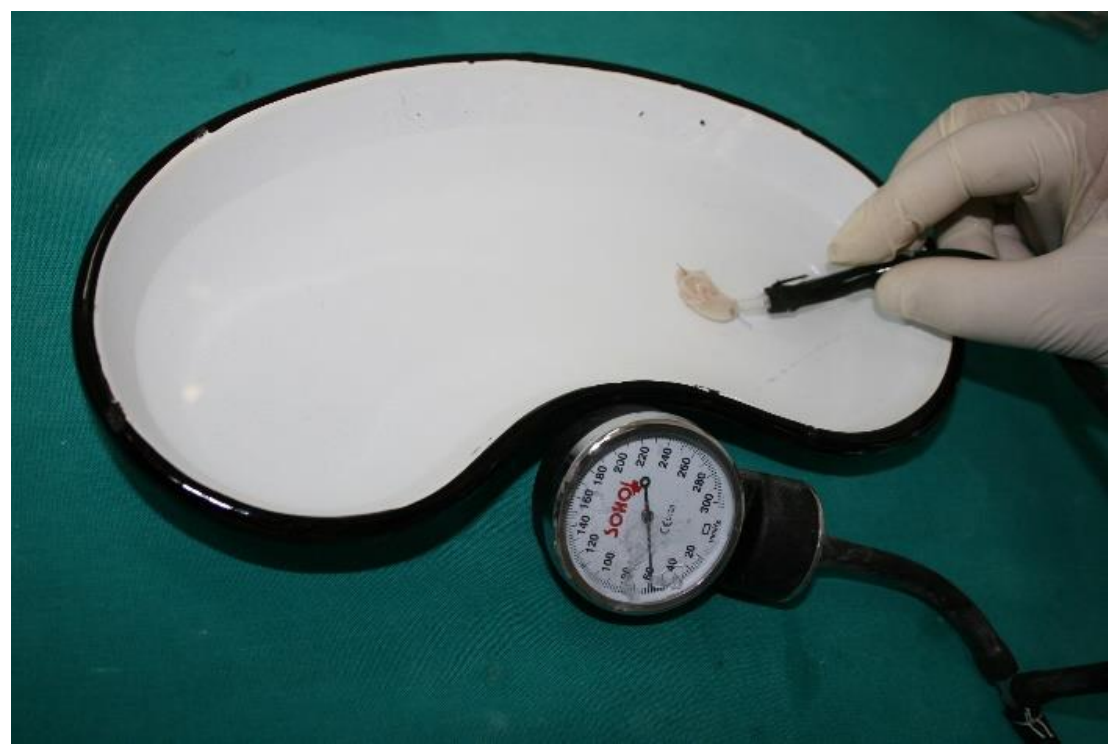

Figure 8: Immersion testing of anastomosis resistance to pressure.

After completing the previous stages, the resection of the digestive tract segment containing the gastro-jejunal anastomosis with a safety margin of approximately 5-10 $\mathrm{mm}$ is performed, considering that at this level is the highest risk of anastomotic fistula. Determine the pressure that the anastomosis withstands with a device like the one in the adjacent figure.
The determination of this pressure is performed by immersion (see figure 8) with the help of a blowing pair and a manometer that records the pressure at which intestinal dehiscence occurs (rupture of the anastomosis). After removing excess tissue, intestinal anastomosis is taken in containers with PFA / formalin to make histology slides in trichrome hemalaun-eosin-methylene blue to assess the degree of fibrosis and granulation tissue. 


\section{Results}

The evolution of the weights preoperatively shows an essential increase in the first interval followed by a certain plateau. In the last interval of time, adding another addition is not so significant as in the first time interval (figure 9).

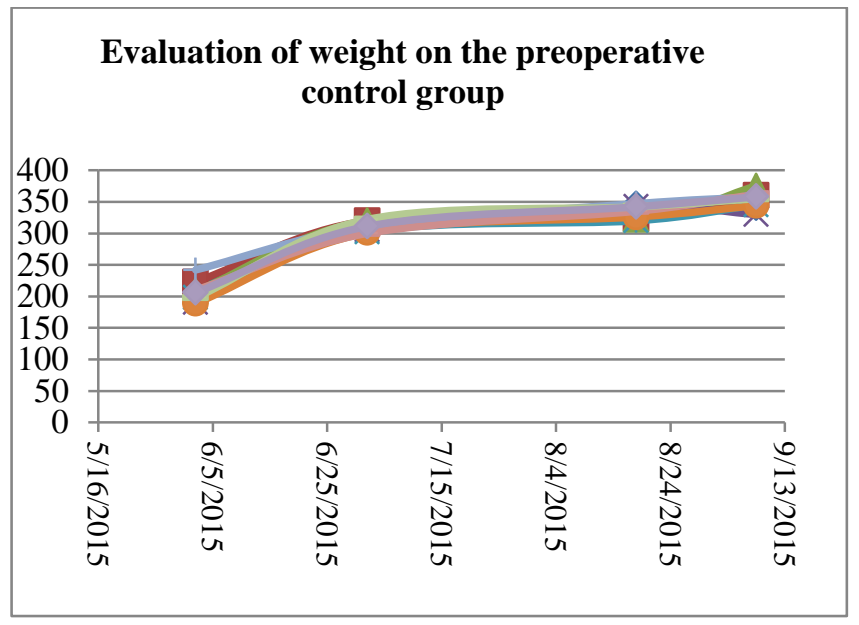

Figure 9: Evolution in time of weight (gr) in preoperative control group.

In the case of the study groups, the rats fed with a hypercaloric diet are observed a constant ascending weight gain, the most significant evolution being also in the first time interval. The difference between the average weights in the control group compared to the study groups is statistically significant, making the diet presented in the methodology chapter an experimental model of obese Wistar rats on which various aspects can be studied. The table below shows a difference of up to 162 grams between the control group and the study groups with a hypercaloric diet, the average being $98 \mathrm{~g} \pm 7.2$ (Mean \pm StDev) between them. The difference is statistically significant $(\mathrm{p}<0.05)$.

As shown in the graph and table below, there is a statistically significant difference between the mean weight in the control group and $\mathrm{B}, \mathrm{BS}$, and $\mathrm{S}$ (values expressed as Mean \pm StDev). I am having the importance of $p$ and Pearson's coefficient described in the table below. The most significant difference being between the control group and the $S$ group (figure 10).

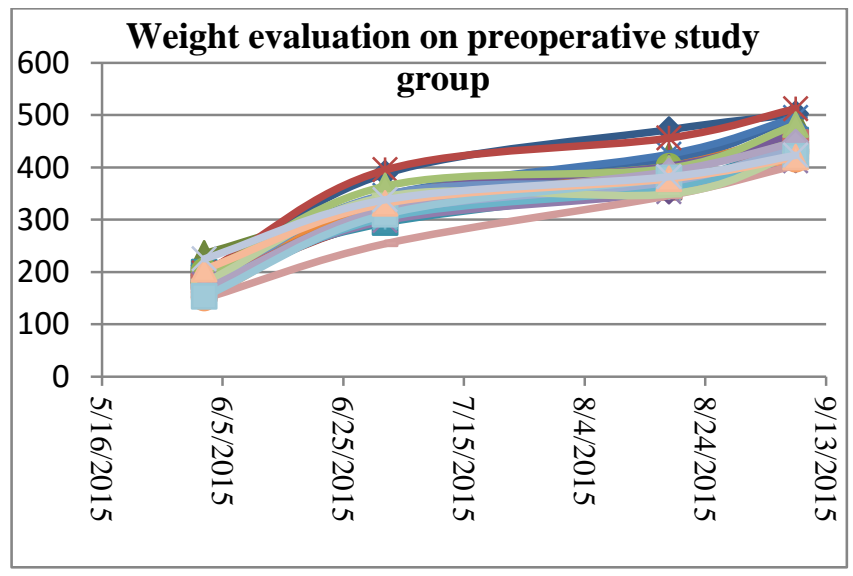

Figure 10: Evolution in time of preoperative study groups in weight parameter (gr)
Postoperatively, groups B and BS's average weight decreases significantly; their values are below the control group (see table below).(figure 12, figure 13) In contrast, the importance of group $\mathrm{S}$ increased by about $19 \mathrm{~g}$ on average. No statistical significance is reported between groups B and BS in postoperative weight, although group BS has a lower average than in group B. However, there is a statistically significant difference (almost 160g) between $\mathrm{B}, \mathrm{BS}$, and group S postoperative.(table 2)

Although small (approximately 40-50 g), the difference between the control group and groups B and BS is statistically significant with $\mathrm{p}=0.016$ and 0.026 and Pearson index of 0.674 and 0.628 , respectively. Statistical significance also kept the difference between group $\mathrm{C}$ and group $S(p=0.028$, Pearson Coefficient $=0.621)$. (table 2 , table 3)

We notice that the weight loss for group B (By-pass) was $125 \pm 16.16 \mathrm{~g}$, and for group BS (By-pass + Sulodexid), it was $133.10 \pm 14.38 \mathrm{~g}$. Although the weight loss was higher in group BS, it is not statistically significantly higher than in group $\mathrm{B}(\mathrm{p}=0.345)$, despite administering a pharmacologically active substance in group BS. (figure 11)

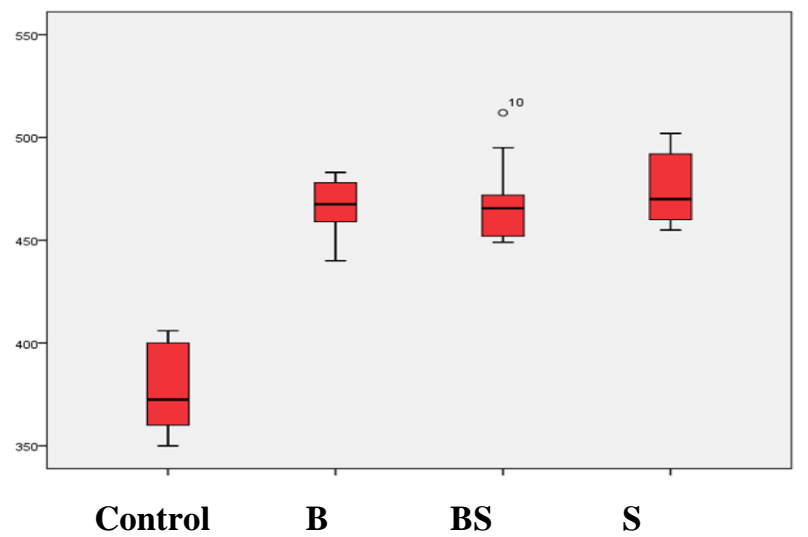

Figure 11: Preoperative weight on each batch (Mean \pm StDev). C: Control 376.30 \pm 19.71 gr, B: $465.50 \pm 12.88$ gr BS: $468.80 \pm 20.32 \mathrm{gr}$ S: $474.70 \pm 16.93 \mathrm{gr}$

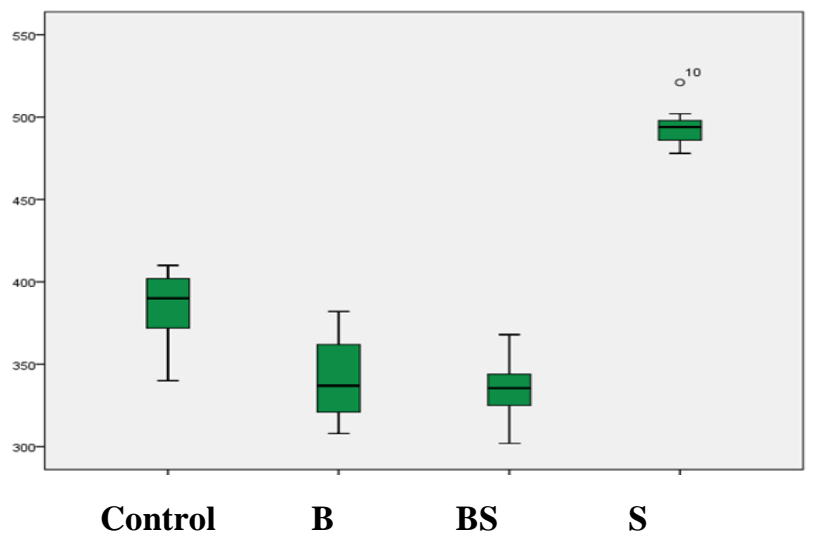

Figure 12: Chart with postoperative weights at 28 days (Mean \pm StDev). C: Control: $383.40 \pm 24.30$ gr , B: $342.16 \pm 24.96$ gr B: $335.70 \pm 18.60$ gr S: $493.90 \pm 12.29$ gr 
Table 2: Evolution and correlations of pre- and postoperative weight differences.

\begin{tabular}{lllllll} 
Group (n) & $\begin{array}{l}\text { Preoperative } \\
\text { Weight }(\mathrm{gr})\end{array}$ & $\begin{array}{l}\text { Postoperative } \\
\text { Weight }(\mathrm{gr})\end{array}$ & P value & Pearson & $\begin{array}{l}\text { Average pre / } \\
\text { postop difference }\end{array}$ & $\begin{array}{l}\text { The significance } \\
\text { of the difference }\end{array}$ \\
\hline C (10) & $376.30 \pm 19.71$ & $383.40 \pm 24.30$ & $\mathbf{0 . 0 5 *}$ & 0.421 & $-7.1 \pm 17.05$ & 0.652 \\
B (12) & $465.50 \pm 12.88$ & $342.16 \pm 24.96$ & $\mathbf{0 . 0 1 2}^{*}$ & 0.691 & $125.4 \pm 16.16$ & $<0.001$ \\
BS (10) & $468.80 \pm 20.32$ & $335.70 \pm 18.60$ & $\mathbf{0 . 0 0 8}^{*}$ & 0.730 & $133.1 \pm 14.38$ & $<0.001$ \\
S (10) & $474.70 \pm 16.93$ & $493.90 \pm 12.29$ & $\mathbf{0 . 0 0 1} *$ & 0.907 & $-19.2 \pm 7.75$ & $<0.05$ \\
\hline
\end{tabular}

* It was considered statistically significant $\mathrm{p}<0.05$

Table 3: Correlations between batches - for the Weight parameter

\begin{tabular}{|c|c|c|c|c|}
\hline & C_post-op. & B_post-op. & BS_post-op. & S_post op. \\
\hline C_pre-op. & $\begin{array}{l}\mathrm{p}=0.01^{*} \\
\text { Coef Pearson }=0.719\end{array}$ & $\begin{array}{l}\mathrm{p}=0.013^{*} \\
\text { Coef Pearson }=0.696\end{array}$ & $\begin{array}{l}\mathrm{p}=0.132 \\
\text { Coef Pearson }=0.390\end{array}$ & $\begin{array}{l}\mathrm{p}=0.013^{*} \\
\text { Coef Pearson }=0.695\end{array}$ \\
\hline B_pre-op. & $\begin{array}{l}\mathrm{p}=0.014^{*} \\
\text { Coef Pearson }=0.691\end{array}$ & $\begin{array}{l}\mathrm{p}=0.016^{*} \\
\text { Coef Pearson }=0.620\end{array}$ & $\begin{array}{l}\mathrm{p}=0.046^{*} \\
\text { Coef Pearson }=0.561\end{array}$ & $\begin{array}{l}\mathrm{p}=0.154 \\
\text { Coef Pearson }=0.360\end{array}$ \\
\hline BS_Pre-op. & $\begin{array}{l}\mathrm{p}=0.074 \\
\text { Coef Pearson }=0.492\end{array}$ & $\begin{array}{l}\mathrm{p}=0.035^{*} \\
\text { Coef Pearson }=0.595\end{array}$ & $\begin{array}{l}\mathrm{p}=0.008^{*} \\
\text { Coef Pearson }=0.730\end{array}$ & $\begin{array}{l}\mathrm{p}=0.033^{*} \\
\text { Coef Pearson }=0.602\end{array}$ \\
\hline S_pre-op. & $\begin{array}{l}\mathrm{p}=0.027^{*} \\
\text { Coef Pearson }=0.624\end{array}$ & $\begin{array}{l}\mathrm{p}=0.102 \\
\text { Coef Pearson }=0.439\end{array}$ & $\begin{array}{l}\mathrm{p}=0.043^{*} \\
\text { Coef Pearson }=0.569\end{array}$ & $\begin{array}{l}\mathrm{p}=0.001^{*} \\
\text { Coef Pearson }=0.907\end{array}$ \\
\hline
\end{tabular}

$*$ It was considered statistically significant $\mathrm{p}<0.05$

Table 4: Correlations of pre- and postoperative weight differences for groups B and BS

\begin{tabular}{|c|c|c|c|}
\hline \multicolumn{2}{|c|}{} & G_Bpreop_Bpostop & G_BSpreop_BSpostop \\
\hline \multirow{4}{*}{ G_Bpreop_Bpostop } & Pearson Correlation & 1 & -.144 \\
\cline { 2 - 4 } & Sig. (1-tailed) & & .345 \\
\cline { 2 - 4 } & Sum of Squares and Cross-products & 2352.400 & -302.400 \\
\cline { 2 - 4 } & Covariance & 261.378 & -33.600 \\
\cline { 2 - 4 } & N & 10 & 10 \\
\hline \multirow{5}{*}{ G_BSpreop_BSpostop } & Pearson Correlation & -.144 & 1 \\
\cline { 2 - 4 } & Sum of Squares and Cross-products & -345 & 1862.900 \\
\cline { 2 - 4 } & Covariance & -33.600 & 206.989 \\
\cline { 2 - 4 } & $\mathrm{N}$ & 10 & 10 \\
\hline
\end{tabular}

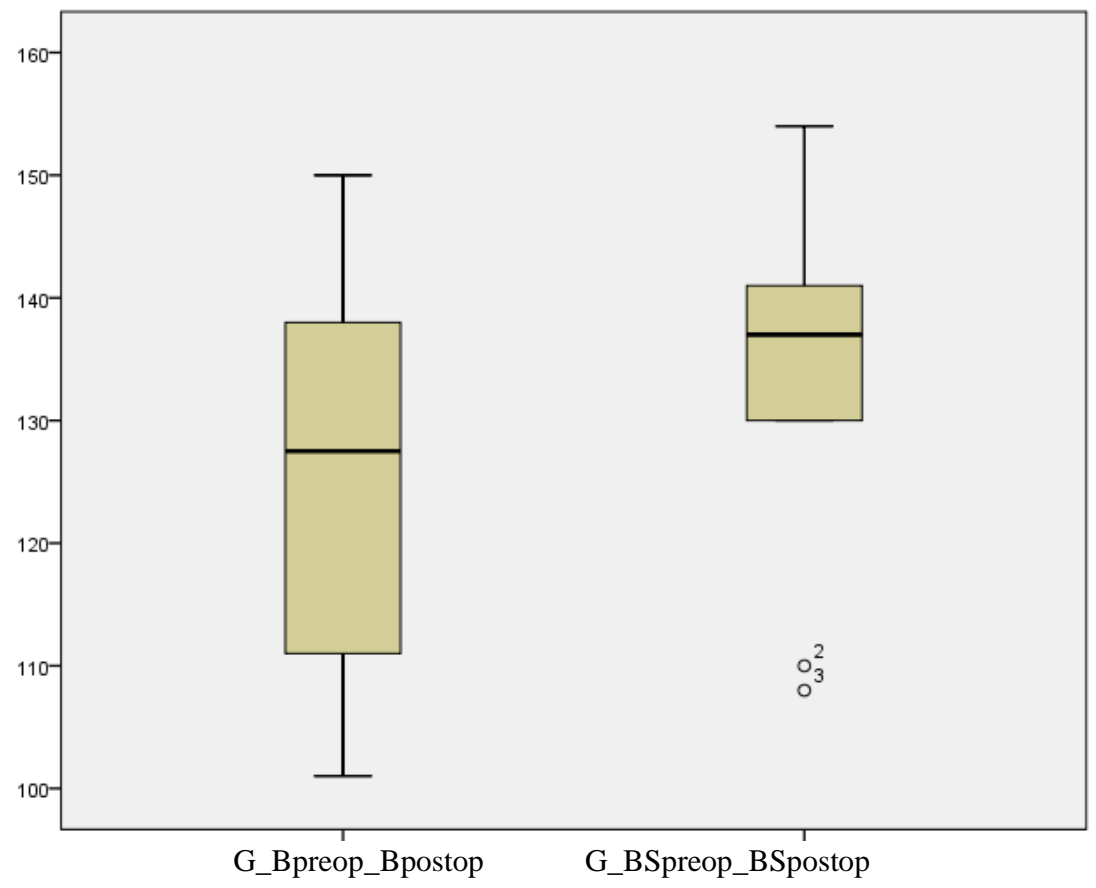

Figure 13: Pre- and postoperative weight difference for groups B and BS (Mean \pm StDev) 


\section{Discussion}

Regarding the diet administered to rats to induce intake obesity, Vincent E. de Meijer et al. showed that a diet consisting of $60 \%$ fat can cause an increased level of the fat index and can generate obesity; it can also induce thus insulin resistance and hepatic steatosis administered for a long time, diseases directly related to obesity. (15-18) The diet administered in our research was achieved by combining a hypercaloric, hyperlipidemic diet, cited in the literature, with a diet present today in most of the population in medium and well-developed countries, a diet rich in high-calorie foods, sweets, and sweet carbonated drinks. It contained $82 \mathrm{~g} / 100 \mathrm{~g}$ fat, 53 / 100g saturated fatty acids, 64 / 100g carbohydrates, were practically fed with $82 \%$ butter and carbohydrate enriched chocolate to reach the stage of obesity. It is considered at weight over 75 percentile according to age. These were added a discretionary diet with granules for rats and water ad libitum enriched with $35 \mathrm{~g}$ of sugar / $100 \mathrm{~g}$ of water (similar to the carbohydrate addition from carbonated drinks). In this way, we tried to simulate as well as possible the conditions in a society where the consumption of fast food and sweet carbonated drinks is continuously increasing(19).

The administered diet determined the appearance of obesity in the study rats, the obesity being considered the weight over the 75th percentile of age. The statistically significant difference in food intake in the study groups compared to the control group that received regular feeding was up to 162 grams, more than half the rats' body weight in the control group. Data from the literature abound in various diets with similar results, important being the final weight at which the recordings are made. (20) It is known that a patient, or in our case, a laboratory subject if he is obese for a significant period, will also develop diabetes in direct relation to obesity induced by food intake. (21)

Postoperatively, the effects of surgery are observed for the weight and blood glucose values and the TGL and CHO values, all registering statistically significant values lower than the preoperative values on the respective groups. The difference is both between pre- and postoperative moments and between groups B, BS, and group Control (C). In addition to the surgery that is the determining factor generating these differences, the rats in the study groups returned to regular feeding After surgery, without a hypercaloric/hyperlipidemic diet and carbohydrate supplementation in the food consumed(22-23).

Given that laboratory animals do not have the same parameters for assessing postoperative weight status, After a thorough study of the literature, we chose to replace the variable\% EBWL, which we can not calculate according to the formula given to rats, not having their height as a welldefined variable, with pre- and postoperative weights difference at 28 days, respectively (22).

Weight loss was the most important in the case of the BS group. In group $\mathrm{B}$, the weight loss, although very significant, did not reach the value of group BS. We can thus suspect that the difference between groups B and BS in terms of postoperative weight loss, the difference in favor of group $\mathrm{BS}$, is due to sulodexide administration, a fact not yet confirmed in the literature. Since sulodexide does not have a role in weight loss, we can consider that its implication in tissue remodeling by changing the status of MMPs is what determines that increase in a weight loss of the BS group. The involvement of sulodexide in MMP metabolism is also demonstrated by Mannello et al. in his study published in 2013. (23)

A meta-analysis with an extremely strong scientific impact published by Ribaric, Buchwald and McGlennon in 2014 in a reference journal for the medical scientific community conducted on a number of 6131 patients with a mean follow-up of $17.3 \pm 5.7$ months revealed 9.8 to 15.8 times the efficiency of bariatric/metabolic surgery compared to conventional therapy in terms of weight loss, reduction of TGL, CHO, HbA1C (glycosylated hemoglobin) and fasting blood glucose. These data implicitly lead to the conclusion of the effectiveness of the surgical treatment of obesity for weight loss and remission of type II diabetes (18).

\section{Conclusions}

First of all, metabolic surgery is the most effective weightloss method and improvement or even remission of some diseases associated with obesity.

Like today's high-calorie diet, the diet administered, mostly of adolescents, generates both obesity and its associated diseases: diabetes, hypertriglyceridemia, hypercholesterolism, thus increasing mortality and overall morbidity.

Second, metabolic surgery radically improves the parameters targeting obesity (weight, $\%$ EBWL) and its associated conditions: diabetes mellitus, hypertriglyceridemia, hypercholesterolemia, strongly associated with decreasing life expectancy of the general population. Parameters targeted by gastric bypass: glycemia, TGL, CHO, hepatic steatosis, testicular atrophy registering significant improvements.

Author Contributions: Radu Mirica, Alexandra Mirica, Octav Ginghina, Razvan Iosifescu, Andrei Vacarasu, Claudiu Ungureanu, Niculae Iordache: Project design, Review of the literature, Data collection Radu Mirica: Writing and Revisions

Conflict of interest: No actual or potential conflicts of interest exist in relation to this article.

Ethical issues: All authors declare originality of research.

\section{References}

1. Boden G, Song W, Pashko L, K. K. (2008) 'In vivo effects of insulin and free fatty acids on matrix metalloproteinases in rat aorta', Diabetes, 57(476).

2. Bouloumié, A. et al. (2001) 'Adipocyte Produces MMP2 and 9 Involvement in Adipose Differentiation', Diab, 50(9), pp. 20802086.

3. Booth, H. et al. (2014) 'Incidence of type 2 diabetes after bariatric surgery: Population-based matched cohort study', The Lancet Diabetes and Endocrinology. Booth et al. Open Access article distributed under the terms of CC BY, 2(12), pp. 963968.Broekhuizen, L. N. et al. (2010) 'Effect of sulodexide on glycocalyx and vascular permeability in patients with type 2 diabetes', Diabet, 53(12), pp. 2646-2655. 
4. Mirica, R. M. et al. (2017) 'Quality of Life Assessment After Metabolic Surgery - a Single-Center Experience'. Indian Journal of Surgery.

5. Mirica, R. M. et al. (no date) 'The Important Roles of Matrix MMP in the Pathophysiology of Obesity', pp. 1481-1484.

6. Mingrone, G. et al. (2015) 'Metabolic surgery versus conventional medical treatment in obese patients with type 2 diabetes: 5 Year follow-up of an open-label, single-centre, randomised controlled trial', The Lancet. Elsevier Ltd, 386(9997), pp. 964-973.

7. Nickel, F., Schmidt, L., Bruckner, T., Billeter, A. T., et al. (2017) 'Gastrointestinal Quality of Life Improves Significantly After LSG and RYGB - a Prospective Cross-Sectional Study Within a 2-Year Follow-up', Obesity Surgery. Obesity Surgery, 27(5), pp. 12921297.

8. Nickel, F., Schmidt, L., Bruckner, T., Büchler, M. W., et al. (2017) 'Influence of bariatric surgery on qol, body image, and general selfefficacy within 6 and 24 months - a prospective study', Surgery for Obesity and Related Diseases. Elsevier, 13(2), pp. 313-319.

9. Nicolae Angelescu, F. P. (2010) Caiet de tehnici chirurgicale

10. Noel P, Nedelcu M, Nocca D, Schneck AS, Gugenheim J, Iannelli A, G. M. (2014) 'Revised sleeve gastrectomy:an option for weight loss failure after LSG', Surg Endosc, 28(4), pp. 1096-1102.

11. POPESCU, L.A., VIRGOLICI, B., STEFAN, D.C.A., LIXANDRU, D., TIMNEA, O., VIRGOLICI, H., ORASEANU, D., SINESCU, C., MOHORA, M. (2017) 'Vascular Reactivity and Proinflammatory Cytokines in the Obese Children', Rev. Chim.(Bucharest), 68(4), pp. $758-768$.

12. Popov Y, S. D. (2009) 'Targeting liver fibrosis: strategies for development and validation of antifibrotic therapies', Hepatology, 50: 1294-3.

13. Qin DD, Yuan W, Z. W. (2007) 'Do reproductive hormones explain the association between body mass index and semen quality?', Asian J Androl, 9, pp. 827-34.
14. Regan JP, Inabnet WB, Gagner M, P. A. (2003) 'Early experience with two-stage laparoscopic RYGB as an alternativein the super obese patient.', Obes Surg., 13(6), pp. 861-864.

15. Ress, C. et al. (2010a) 'Influence of significant weight loss on serum MMP-7 levels', European Cytokine Network, 21(1), pp. 65-70.

16. Ress, C. et al. (2010b) 'Influence of significant weight losson serum MMP-7 levels', European Cytokine Network, 21(1), pp. 65-70.

17. Reynolds, C. L., Byrne, S. M. and Hamdorf, J. M. (2017) 'Treatment Success: Investigating Clinically Significant Change in QoL Following Bariatric Surgery', Obesity Surgery. Obesity Surgery, 27(7), pp. 1842-1848.

18. Ribaric, G., Buchwald, J. N. and McGlennon, T. W. (2014) 'Diabetes and weight in comparative studies of bariatric surgery vs conventional therapy:A review and meta-analysis', Obesity Surgery, 24(3), pp. 437-455.

19. Sacks, J. et al. (2018) 'Effect of RYGB on liver mitochondrial dynamics in a rat model of obesity', Physiological Reports, 6(4), p. e13600.

20. Salminen, P. et al. (2018) 'Effect of LSG vs LRYGB on Weight Loss at 5 Years Among Patients With Morbid Obesity', Jama, 319(3), p. 241.

21. Santoro, S. et al. (2014) 'Sleeve gastrectomy with anti-reflux procedures', Einstein (São Paulo), 12(3), pp. 287-294.

22. Serra, R. et al. (2014) 'The effects of sulodexide on both clinical and molecular parameters in patients with mixed arterial and venous ulcers of lower limbs', pp. 519-527.

23. Sierżantowicz R1, Lewko J2, Hady HR3, Kirpsza B1, Trochimowicz L3, D. J. (2017) 'Effect of BMI on quality of life and depression levels after bariatric surgery.', Adv Clin Exp Med, 26(3), pp. 491496. 